\title{
SuDS and human behaviour: Co-developing solutions to encourage sustainable behaviour
}

\author{
Glyn Everett'.a , Jessica Lamond²
}

${ }^{1}$ Centre for Floods, Communities and Resilience, University of the West of England, Bristol, United Kingdom, BS16 2BP

${ }^{2}$ Centre for Floods, Communities and Resilience, University of the West of England, Bristol, United Kingdom, BS16 2BP

\begin{abstract}
Sustainable Drainage Systems (SuDS) are today widely considered to be a more progressive and environmentally sensitive approach to Flood Risk Management (FRM). However, this paper argues that the sustainability of SuDS should not be so simply presumed. Devices will depend upon correct behaviour from those local to them in order to function properly over time, and for Green Infrastructure SuDS to flourish and deliver their promised multiple benefits. This paper looks to the potential value in using Social Practice Theory as a lens for understanding current behaviours around SuDS devices, and for assessing possible strategies for encouraging positive behaviour amongst affected communities. It concludes in arguing that involving local people as much as possible in the co-design of systems and then working to maintain involvement and awareness will be the most cost-effective means by which SuDS might be made to live up to the sustainability they are celebrated for.
\end{abstract}

a Corresponding author: glyn.everett@uwe.ac.uk 


\section{Introduction}

Sustainable Drainage Systems (SuDS) are today generally regarded as a more progressive approach to Flood Risk Management (FRM), Green Infrastructure forms of which also promising to improve water quality and create more 'liveable' urban environments with improved aesthetics, air quality and biodiversity. Thinking has begun moving away from using structural defences toward establishing softer and more sustainable FRM that retains, filters and makes use of water-flows. A small but growing number of authors have published work around public attitudes to SuDS systems, producing mixed findings concerning preferences around structural and sustainable FRM, aesthetics and perceived safety levels around open green and blue spaces. This is a crucial issue, since what is often seemingly overlooked is that people's attitudes will affect their behaviour, and SuDS will only ever be as sustainable as the behaviour that surrounds them.

Further, what has not yet been done is to think about how public behaviours might change over time, and how different factors might influence more and less sustainable behaviour change. This paper builds upon published research using a number of qualitative case studies from 2013-2016 in England and Portland, Oregon USA. It firstly details the levels of engagement people local to SuDS had in their development, and considers levels of understanding, appreciation and corresponding behaviour. It then outlines and employs Social Practice Theory as a framing device for understanding the formation and reproduction of 'good' and 'bad' practices and behaviours, considering how these might develop and alter under various conditions and with different interventions. It assesses how longer-term engagement, consultation and co-development of SuDS solutions might help to engender more awareness, acceptance, appreciation and so positive practices. This engagement, it is suggested, should be ongoing, to cope with changes in household occupation and broader socio-demographic shifts. Longer-term enculturation of SuDS systems might in this way be encouraged such that positive maintenance practices became more widespread, heightening appreciation of devices and so desire for them to flourish and/or function well. The paper concludes in arguing that the wider social and ecosystem service benefits arising from the collaborative development and maintenance of SuDS would be to the benefit of society and the economy as a whole.

\section{UK Flood Situation and Responses}

There are estimated to be roughly 5.5 million properties in England and Wales currently at risk of pluvial, fluvial, coastal and surface water flooding $[1,2]$. This increases to 6 million for the UK as a whole, of which 560,000 are deemed to be at 'significant risk' (greater than 1:75 likelihood) [3]. Globally, risks from flooding are an ever-greater concern [4]; an estimated almost 1 billion people around the world are currently at risk, and the level of assets at risk has been calculated as around $\$ 46$ trillion [5].

Furthermore, some predict that the effects of climate change could be profound. Following from anticipated increases in frequency and magnitude of extreme rainfall events (Bates et al., 2008; IPCC, 2012), some forecast that flooding will increase in both severity and frequency [5-7]. The UK has been forecast to see a 33 per cent winter rainfall increase and a 40 per cent decrease over the summer [8]. Four of the five wettest recorded years in the UK have occurred in the 21st Century (2000, 2002, 2008 and 2012; [9]). UK flooding has been projected to continue to increase dramatically, by up to 30 times, over the next 75 years [10], and the number of properties at significant risk could potentially increase to $1.5 \mathrm{~m}$ by 2080 [3]. The costs of reparation and protection work could potentially increase to the tens of billions of pounds each year [4, Evans et al. 2008; EM-DAT, 2012]; this will of course be a similar story repeated to varying degrees around the world.

Flood risk will be further worsened by economic and population growth, and concomitant increases in urbanisation; the United Nations [11] estimates that twothirds of the global population will be living in urban areas by 2050 . Increasing urbanisation will place greater numbers of people, housing and so urban infrastructure on floodplains [12], as well as increasing the extent of impermeable surfaces as vegetated water-draining land is covered with housing, retail, roads and hard-standing (footpaths, car parks), increasing surface run-off [13]. As such, it is clear that more needs to be done to help mitigate flood risk and develop individual and social resilience.

\section{The SuDS R/evolution}

Thinking at governmental policy level in many parts of the world has begun shifting away from simply seeking to resist inundation outright and towards 'living with water' [6] and 'making space for water' [7]; moving away from hard 'grey' infrastructure and towards more sustainable drainage, including 'Blue-Green' Infrastructure (BGI) approaches. BGI refers to bringing water management and green infrastructure together in order to help return the water cycle to a more naturally oriented state, whilst also contributing to the amenity of the built environment [14].

Beyond simply flooding, governance institutions are treating seriously the need to deal with social, environmental and economic threats coming from excesses, lacks and poor qualities of water. The Government of South Australia and Singapore have adopted and are pursuing the Water Sensitive Urban 
Design approach developed and advocated by Professor Tony Wong of the Co-operative Research Centre for Water Sensitive Cities [15]

. The European Union has implemented both the Water Framework Directive and Floods Directive [16,17], committing members to developing flood risk assessments for their territories and working to improve water quality. Within this, the 'Room for the River' programme [18] in the Netherlands has been developed to enhance environmental conditions around rivers, and flood protection, whilst all United Kingdom governments are over time looking to change their approaches to dealing with flood threats using more sustainable approaches [19-22].

The United States, meanwhile, has allocated significant time and money through its Environmental Protection Agency (EPA) to exploring the potential for using green infrastructure to reduce social and economic costs of flooding [23,24]. 'Green Infrastructure' [25] has been being promoted for around 20 years in the US for environmental, economic and social reasons, and since the turn of the millennium this shift in focus to blue-green thinking has taken hold. The city of Portland, Oregon is widely thought of as a leading city in the US and internationally for its pursuit and implementation of such approaches, scoring highly in Portney's [26] review of US cities for sustainability efforts (see also [27]). It has done this based on efforts to reduce 'nuisance' flooding (more minor 1:10 floods that nevertheless block roads and cause basement and house flooding, as well as worsening water quality with industry and road run-off, [28]), enhance liveability, encourage sustainable development practices and adapt for climate change ([29,30]).

Moving away from 'grey' infrastructure defences and towards use of SuDS cannot be simply an undertaking of governments, national, regional or local, however. It will require the involvement of all the local publics who will be affected, in order to encourage the development and adoption of new practices and behaviours that can help ensure functionality and sustainability. Questions will need to be asked about where public preferences currently lie, and how they might develop, positively or negatively, with the wider rollout and adoption of SuDS. Unlike frequently more hidden grey infrastructure, SuDS will often change the visible makeup of an urban environment: swales, rain gardens and green roofs will require finding space to locate green devices around or on top of buildings, permeable paving and rainbarrels will change the aesthetics of homes and surrounds and permeable paving will further alter the 'feel' of the ground. New ways of thinking about what flood risk management involves and looks like will be needed if devices are to be successful [31]; they will require developments in the behaviour of those who live and work around them if they are to perform to standard over time. Understanding perceptions and behaviours of local publics will be vitally important. 'Sustainable' Drainage Systems can only be as sustainable (in the sense of functioning service life and so Life Cycle Analysis assessment) as the behaviour of those who live around, visit or pass by them.

\subsection{Existing Research}

Hypothetical reasoning around the value of SuDS systems has been undertaken, producing the 'SuDS Triangle' which proposes that SuDS sit at the centre of a Venn diagram (Figure 1). The assumption is that a well-managed SuDS system will help reduce water quantities, improve water quality and further provide amenity and biodiversity benefits.



Figure 1: SuDS Triangle [32]

The amenity arm of the SuDS triangle is however arguably the most important from a social and a sustainability perspective. People will need to understand SuDS' direct functions (improving water quality and reducing flooding), and notice and appreciate their more indirect benefits, such as adding green infrastructure, to comprehend how they might contribute to amenity (such as providing wildlife corridors to encourage biodiversity, improving air quality and aesthetics, and providing 
recreation and leisure spaces that can benefit physical and mental health). If they do not feel devices contribute to their lives, they might be less willing to adapt behaviour to facilitate longer-term functioning, or to pay for their wider rollout and maintenance.

'Amenity' is a frequently referenced benefit of SuDS [33-35], yet the perceptions, preferences and understandings of those who live around devices are under-researched. A number of UK studies have been done, with contrasting results. Werritty et al. [36] conducted work in Scotland, finding that the great majority of their respondents $(90 \%)$ thought that structural defences will be most acceptable form of defence in terms of cost, fairness and effectiveness; less than $80 \%$ supported SuDS systems and increasing upstream storage through the payment of land managers. Johnson and Priest [37] evaluated the possibilities for undertaking more SuDS work, but came to the conclusion that the public, the insurance industry and the media were all still at present too fixed upon the use of structural defences for alternatives to become mainstream. Kenyon [38], again studying in Scotland where approaches have been being pursued for longer than anywhere else in the UK, found that the people she surveyed expressed distinct preferences for sustainable drainage approaches such as the regeneration or planting of native woodlands (and showed least preference to structural defence work). Apostolaki and Jefferies [39] meanwhile found that their surveyed publics most preferred sustainable, 'greener' approaches such as ponds, as these enhanced amenity and recreation opportunities within the places they were located more than any structural work could.

Two further UK studies have also noted public preferences lying generally with more sustainable approaches [40,41], again finding that ponds were valued for helping wildlife, and improving amenity and aesthetics. A couple of studies from Portland, Oregon around the Tabor to the River Program (T2R) have looked at public perceptions of 'bioswales', highlyengineered rain gardens designed to reduce surface water run-off as well as cleaning the water before it returns to the main rivers. Shandas et al. [31,42] and Church [43] both found that residents liked having bioswales and judged neighbourhoods with them more highly than those without.

\section{Social Practice Theory (SPT)}

If we are to consider how different groups might respond to SuDS, and how perceptions and behaviours could change over time, then we will require a clear understanding of the 'units' under consideration and the de/stabilising influences that could affect these.

Social theorists have for some decades been working to move beyond the restrictive dualism of deterministic structuralism and rationalistic atomism that much theory has thus far been broadly divisible into [44]. Under structuralism it is social norms, values and 'rules' that determine human behaviour, this being 'an 'effect' of symbolic structures in the 'unconscious' mind' [45]. With atomism, by contrast, rational individuals are taken as the units of agency, working to advance their own interests once they have assessed all costs and benefits (homo economicus).

One attempt to move beyond this seeming dualistic theoretical impasse has been the production of a 'family' of 'theories of social practice', influenced by the later Michel Foucault, Anthony Giddens, Pierre Bourdieu and others. Social Practice Theory (SPT) assumes a both/and position with regard to this presumed dualism, in looking to overcome the agency/structure divide, instead considering the series (or complex) of practices of groups of individuals [45]:

Practice refers to a collection of factors 'constitutive of particular domains of social life' (industry, business, farming, teaching, voting, religion, recreation), a set of considerations shaping how people act [46]:

A practice is a routinized type of behaviour which consists of several elements, interconnected to one another ... A practice - a way of cooking, of consuming, of working, of investigating, of taking care of oneself or of others, etc. - forms so to speak a 'block' whose existence necessarily depends on the existence and specific interconnectedness of these elements, and which cannot be reduced to any one of these single elements. [45]

As Schatzki states, a practice 'rules action not by specifying particular actions to perform, but by offering matters to be taken account of ... it qualifies the how as opposed to the what of actions'. Sets of practices form 'shared behavioural routines', argued to be coconstitutive of individuals; actors thereby retain their agency, within a context. They will 
continually reproduce various social practices, but through the enactment of their individual agency will contribute to repetitions, shifts and alterations at each turn. What distinguishes this approach is that the unit of analysis is the set of social practices rather than the individual agents [47].

This approach to practices supports neither structuralist determinism nor atomistic individualism. Practices (and so behaviour) will develop iteratively through repetition, with the contribution of thousands of individual acts of agency within the framing of a dominant 'practice' form: '[t]he concept of practice inherently combines a capacity to account for both reproduction and innovation ... practices also contain the seeds of constant change' [48]). As practices are continually re-performed, different actors will hold to older variants, perform currently dominant types and look to remodel conventions. Social, political, economic and technological developments will affect the development of practices, as will cultural and historical influences [49].

Shove [50] summarises the three elements framing the production and reproduction of practices as materials, meanings and competencies (Figure 2). Materials are the composite of physical artefacts that are required for the performance of a practice (with SuDS, these will be both the devices themselves as well as any tools required for engagement with lowlevel clearing and maintenance). Competencies are the skills and knowledge that actors require to re-perform practices on a daily basis (with SuDS this would be an understanding of an appropriate 'look' for devices and the flora that should and should not be present, as well as the skills to undertake low-level clearing and maintenance work). Meanings refers to the norms, conventions and social understandings that are central to the ongoing re-performance of non-damaging, and clearing and maintenance behaviours. Again with SuDS, this would pertain to people's understanding of the direct immediate and multiple potential benefits of devices, and how the behaviour of themselves and others might encourage or inhibit the realisation of these benefits.

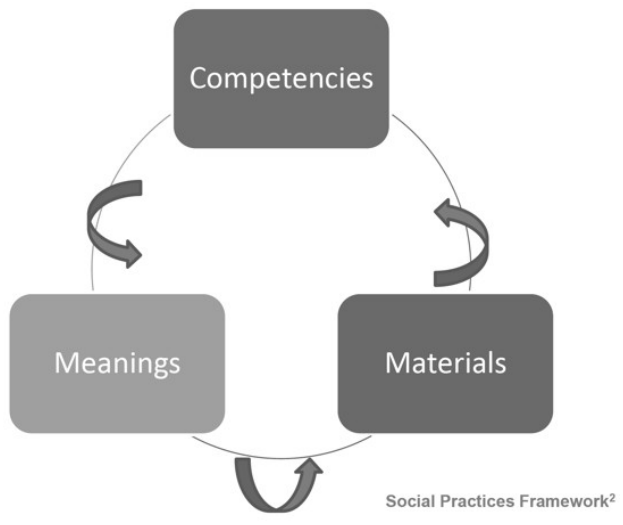

Figure 2: Social Practice Theory circle [50]

Social Practice approaches are gaining traction within environmental social sciences exploring opportunities to encourage the greening of consumption and resource-use [5155]. Research has alerted us to the fact that awareness in itself is a 'weak predictor' of behaviours, meaning we should look elsewhere for possibilities of social change [47]. Parallels can be drawn directly with the various shifts in social practices that will need to occur in order for $\mathrm{SuDs}$ to be sustainable over the long-term.

Shove and Southerton [26] quote Hackett and Lutzenhiser [56], who observe that: '[w]hat [objects] are good for is a consequence, not a determinant, of their use ... they have consummatory as well as instrumental meaning'. This is centrally relevant for all SuDS schemes, where use will impact positively or negatively upon perceived function, benefits and costs and so feed back to influence likely trends in further behaviour.

\subsection{SPT and SuDS}

Whilst SuDS will be installed for flooding, amenity and biodiversity purposes, the latter two terms are still under-defined and open to contestation. As Singleton [57] has acknowledged, the Amenity and Biodiversity arm of the SuDS Triangle is frequently underconsidered. As he argues, 'sometimes it is sidelined, or even forgotten completely' [57]. This is possibly because, as he acknowledges, targets for 'amenity' can be hard to set and outcomes in turn vague. There are further still no overall agreed measurement metrics, scales of assessment [58,59] or formulae for measuring biodiversity and connecting this back to how it would benefit 'amenity' [60].

'Amenity' will only gain substance as a critical mass of facility users develop new 
practices allowing amenity services to become evident, facilitating a transition whereby greater numbers also begin to alter practices, such that the benefits become more widely visible, even measurable. In applying SPT to practices around SuDS installations, research would look to future potential behaviour from current stated preferences and behaviour. Examples of behaviour change over time would be explored using SuDS devices installed some years previously, accepting that the socio-economic and cultural context in each case will necessarily differ from proposed systems.

Using SPT as a lens of analysis could facilitate researchers exploring how different sets of practices might encourage or discourage the sustainability of $\mathrm{SuDS}$ systems, and evaluating the framing approaches from authorities and others that might open up ways for shifts in practices to spread in order to increase sustainable behaviours.

Materials: With existing systems, all materials in the sense of the actual SuDS devices will be in place; tools for low-level maintenance and clearing might already be present in people's homes, or would hopefully be easilyenough accessible (this is something where very small grants, subsidies or vouchers from Local Authorities could help ensure a wider distribution). With proposed systems, engagement of residents in their co-design could help to ensure that the materials fitted more appropriately to local preferences; this could in turn work to positively change their perceived Meaning. In both cases, some element of redesign and retrofit will inevitably occur, and so maintaining some level of local engagement would be helpful in encouraging more positive perceptions of Meaning as well as ensuring that low-level maintenance and clearing were achievable aims.

Meaning: Whilst the principal purpose of SuDS devices will be for reducing flood risk and improving water quality, there will also as mentioned be a wide range of hoped-for multiple further benefits. These will, depending on whether they are perceived and/or believed and appreciated, be the meanings that local residents and users attach to the devices. Increased biodiversity, improved greenspace, improved air-quality, educational opportunities, spaces for relaxation, fresh air and exercise and so on. It is important that people realise and appreciate these benefits in order for them to carry any actual value. Involving them in preinstallation co-design, encouraging feedback and then involving them again in any redesign and retrofit could help improve meaning both by fostering a sense of co-ownership and increasing the likelihood that devices fit as well as possible with local preferences.

Competency: This will pertain to both awareness of good and bad behaviour, an an understanding and technical proficiency to engage with low-level clearing and maintenance where appropriate, and an awareness of appropriate and inappropriate plant matter to be seen in and around devices.

\section{5 'Sustainable' Flood Risk Management and People}

\subsection{Materials: Awareness}

It would appear that there may be general public preferences for using sustainable approaches over hard structural defences, although it is important to ask whether this reflects simply a preference for more green infrastructure in the built environment. A number of studies around green infrastructure have found similarly that preferences often favour such [61,62] [63] [64] [65,66], and that it can contribute to general happiness levels $[67,68]$. Apostolaki and Jefferies [39] found low levels of awareness of local schemes' functions, with many respondents unaware of either the term 'SuDS' or the ponds' contributions to flood-control; Bastien et al. [41] found that public awareness of pond functions at their chosen sites was higher, although awareness of safety levels was markedly different from professional assessments of the safety.

Studies from the US also indicate low levels of understanding and awareness [69], [70]. LaBadie (2010) found poor knowledge of design, construction, maintenance and funding in Albuquerque, New Mexico and observed how this could negatively impact upon willingness to consider alternatives. Similarly, [31] stressed the need to improve knowledge of stormwater management techniques, having observed significant variance amongst neighbourhoods in their studies in Portland. Others have observed misconceptions regarding SuDS harbouring increased populations of mosquitoes [71] [72]), which could in turn negatively affect perceptions. Everett et al. [72,73] conducted work in Portland, Oregon and the South West of England, finding that the great majority of those who expressed an understanding of $\mathrm{SuDS} /$ 
functions believed they would work. However, amongst those who indicated a weaker understanding of functioning were larger numbers who questioned whether they could do all that was claimed.

These studies together indicate the latent potential for public support, with appropriate engagement and awareness-raising, and emphasise the need for early and then on-going public consultation, to help raise and maintain awareness and public approval over time.

\subsection{Meaning: Understanding}

Studies undertaken in the US (Portland, Oregon) and UK have demonstrated an all-too common sense of non-engagement amongst local populations [72,73]. A significant proportion of respondents to postal surveys and interviews said that they had not been consulted about the decision to have installations, their allocation or their design.

This could be attributable to: a lack of serious and ongoing attempts at engagement by system developers pre- and during installation; that people easily forget one-off and more standard procedure engagement methods due to their leading busy lives, or simply that fact that populations inevitably change over time and so a proportion of those who were once engaged will have now moved on:

Bristol \#3 (Site 1): I do know about the Suds because it came in when I was here ... we were consulted on what went in ... So I'm aware that we haven't got flooded when everyone else got flooded.

Bristol \#2 (Site 1): When you came to our [residents'] meeting ... I think it was only me and [Bristol \#1] who had any idea what you were talking about!

Stroud \#1: I think ... about education. Sometimes, we forget to tell newcomers ... they need to know because they have to learn how to run it ... it's up to us to tell the story to newcomers.

As a consequence, understanding of facility functions were often not as strong a might be hoped. In Portland, the highly visible bioswales (Figure 3) were sometimes not understood at all, or were thought to be merely decorative:
Portland \#4: I'm glad that you told me what the hell it is. I had no idea, I didn't know what that was.

Portland \#3: You educated me - I didn't know it's for the water. I just thought it's pretty, and it looks nice for the neighbourhood.

In Stroud, where the fully-integrated SuDS system was again a very visible feature of the site, some residents were nonetheless unaware of their functioning, unless they had been involved with showing other interested parties around the site:

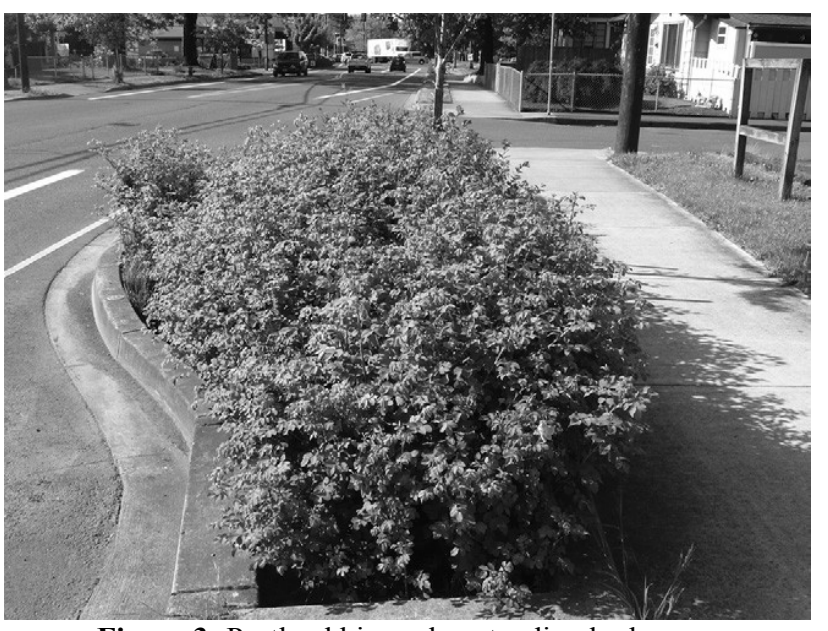

Figure 3: Portland bioswale extending kerb

Researcher: Are you aware of the different water drainage systems around [the estate]?

Stroud \#2: I saw that they were there, but I didn't know anything about it ... I was completely unaware of them ... We take lots of people round and I was aware of them after I'd been on a tour.

Finally, in Bristol, where permeable paving had been installed in an area ten years' previously and kerbs removed (Figure 4), two long-time residents had no idea of the system's existence or purpose:

Bristol \#1 (Site 1): I thought it was mainly just to be flat for people, for wheelchairs, pushchairs - making it safer. 


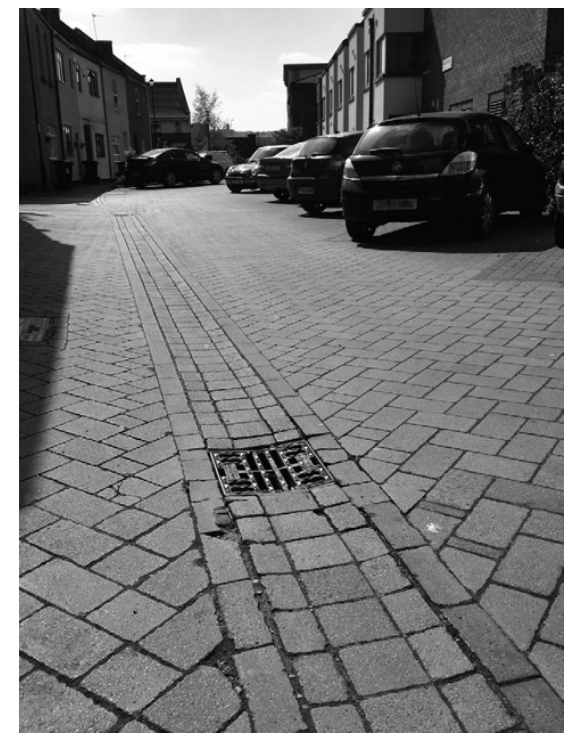

Figure 4: Permeable paving in Bristol, UK

Bristol \#4 (Site 1): I see that these streets, they look different to other kinds of streets, but before you came to ask us, I didn't really take any notice of the draining system ... what does it, it's the water, is that right?

\subsection{Meaning: Willingness to Pay, to Help Maintain and Clear}

A number of respondents (more and less significant minorities) at all sites studied expressed a willingness to engage with the cleaning and maintenance of devices, particularly those closest to where they lived:

Interviewer: 'Would you be happy to be involved with maintenance?'

Portland \#4: 'If it was the one in front of my house, yeah! I'd probably go out every day.'

Bristol \#4 (Site 1): The community group would definitely get involved in maintaining it - if I knew how to fix it outside my front door, I would ... I wish I'd known about it sooner, and I wish I knew more.

Portland has a volunteer Green Streets Stewards (GSS) programme which trains people to know which plants should be in the bioswales and how to trim and weed them [74]. Whilst they do not want untrained residents weeding (see Figure 5), they encourage people to clear out trash and debris [74]. A small number of respondents across installation dates expressed a willingness to get involved with the GSS:

Interviewer: 'The City's encouraging a Green Streets Stewards Scheme to get volunteers to keep it all working ... would you be part of that?'

Portland \#6: 'Yeah sure, we could do that ... People like to do that kind of stuff around here.'

From such small interactions, we cannot be sure to what extent this was true intent, or respondent and/or self-selection bias [75,76], however in a North-East site we also found that over $30 \%$ of respondents to a postal survey agreed they would be happy to engage with maintenance and clearing. If only half of these could actually be recruited, this would still represent a small army of support for helping to keep systems working and providing their multiple benefits to surrounding communities.

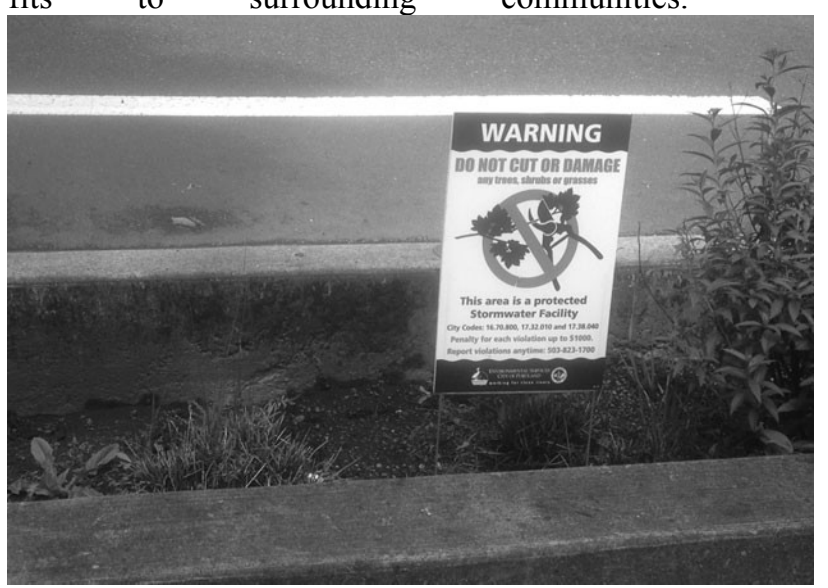

Figure 5: Portland City sign warning against bioswale interference

Others however felt unhappy about the condition of their SuDS systems, although they indicated no willingness to get involved with helping, seeing it as 'their' (the authorities') problem:

Portland \#12: What I don't like is they don't maintain - look how sloppy it is over there, right next door, the grass needs mowing and the tree at the bottom needs to be trimmed off.

Some UK respondents felt that they had paid their taxes, and so this should cover any maintenance that was needed. This again indicates people's sense of devices as an external imposition, the Council's problem, rather than something they have chosen, that will reduce problems (flooding) and could provide benefits (amenity) to the community, that they might 
want to take some ownership of:

Bristol \#6 (Site 1): We would hope that ... Council Tax pays for that. We would not expect to pay on top of that, and people would not expect to be doing voluntary stuff on top of that.

North East \#1: I think I pay enough to manage our site ... we should not need a volunteer group to pick up waste.

Even within a co-housing venture (co-operative housing is designed to encourage more 'community' living and behaviour), one respondent noted that other residents did not do their designated hours of community work simply because it was 'not fun'. This strongly emphasises the need to try andn ensure that voluntary work around devices is made as easy, and 'fun', as possible. Encouraging community activity days where groups of people work together might be one first easy step in this direction:

Stroud \#3: It feels such a chore, getting your hands all muddy, cold water, it's not fun ... We're supposed to do $20 \mathrm{hrs} / \mathrm{yr}$ to support the community ... a lot of people do more than 20 and some don't do even an hour. In the list of jobs done, SuDS maintenance isn't a particularly attractive one.

Some residents in Portland expressed a will to maintain the spaces, so that they could keep them looking neater and tidier rather than to maintain optimal functionality, although with some guidance this willingness to get involved could hopefully be steered toward making positive contributions. However, as is clear from the two quotes below, knowledge about the Green Street Stewards scheme was far from mainstream, and so people presumed their non-engagement was the only approved behaviour:

Portland \#8: We can't touch it. We can't even come out here and trim it ... I wish they would come and just trim. If I could get a weed-cutter and just trim that, it would be great.

Portland \#15: I don't know if I'd want it on my property. I can't touch it - to me, I'd want to cut the ... I would change the plants for sure.
The will of the City of Portland to engage local residents in helping with the bioswales together with these quotes indicating a complete lack of awareness for some concerning the City's desires, point to an arguable value in scaling up and out endeavours to inform and engage local residents. The argument against would usually concern cost, but if the result of such expenditure were to help raise the mentioned small armies of volunteers, in the process raising awareness of good and bad behaviours, and hopefully improving such amongst those who undertook training as well as some of their neighbours, peers and family, then the payback in money saved by authorities might hopefully outweigh any expenses.

\subsection{Competencies: Understanding 'Good' and 'Bad' Behaviour, and Maintenance}

As a result of low levels of awareness as to the existence, purpose and functioning of SuDS systems, many residents were unaware of how their behaviour might interfere with drainage and water-cleansing functions, nor how they might be able to help maintain devices' functioning through some low-level clearing and maintenance work.

In Portland, some clearly did not understand how the devices were designed to operate and so acted, presumably unknowingly, to reduce or negate their functionality:

Portland \#6: Somebody, about a year ago, had these little bean-bag, berries in the intake and it was blocking it - somebody was trying to deliver water from them...

Portland \#11: Somebody in this one right here, didn't they pull some parts up out of it? They exchanged the plants, they'd choose the plants especially to do what it's not supposed to do.

A good number of Portland residents were further ignorant of the fact that litter could clog bioswale outlets, and so did not treat them appropriately:

Portland \#19: Have to be a lot of litter to clog it up. Someone would have to drop their garbage can in there once a week for a month.

Portland \#17: There's always a problem with people throwing garbage around. 
Even my elderly neighbour, a gardener, would throw garbage into his swale; he didn't understand its purpose and he never saw its beauty unfold.

A few had tried to undertake maintenance work with no engagement. One respondent spoke of her husband treating plants to improve aesthetics. Such uncoordinated efforts at improvements may not be consistent with city design; plants are chosen to remove pollutants from the water, and adding chemical treatments may undermine this goal:

Portland \#21: He's tried to make it look better, to look good with [their garden]. Him and his brother brought home stuff to make the grass look better.

Similarly, with the Bristol permeable paving, some residents were unaware of maintenance and behaviour issues; Respondent \#7 has no idea that maintenance might be necessary, whilst \#8 felt they were being helpful by filling the loose permeable areas with impermeable cement, reducing functionality by acting 'responsibly':

Interviewer: Do you know anything at all about maintenance that might be needed to help it keep working?

Bristol \#7 (Site 1): I don't really, no. I suppose, if weeds grow up... is it meant to maintained?

Bristol \#8 (Site 1): When they put the brick pavers down, what they put it in was some kind of sand/cement thing in between it to stop the weeds growing up and, certainly, I put sand and cement in there to stop the weeds growing through.

At a second Bristol site, employees were equally unaware and so unconcerned about potentially damaging the permeable paving with car oil:

\begin{abstract}
Bristol \#1 (Site 2): People don't really take care of it because they don't really know ... if oil drops on it, you just think 'oh, never mind,' instead of thinking 'oh, we've got to do something about this' ... in terms of behaviour, maybe tenants could be informed a bit more.
\end{abstract}

'Competencies' clearly overlap with 'Meaning' here in that some increased expenditure by authorities could hopefully pay back many times over in reducing maintenance and clearing costs in the longer-term.

\section{Discussion}

As should be clear from the argument presented thus far, there is great scope for improving residents' and other's sense of engagement with and ownership of SuDS devices in ways that could improve both behaviour and willingness to engage with clearing and maintenance that could help improve their sustainability. A proper response to the question of how best to undertake such engagement and awareness-raising is beyond the scope of this paper, although some first thoughts based on reflections upon the gathered data can be put forward for discussion. The aim would be to pursue approaches that encourage the development of senses of ownership and so responsibility. The hope would then be that these developments could begin to affect those around he affected in such a way that the changes in perceptions and behaviour could begin to spread virally, and/or then snowball, such that positive behaviour gradually became more mainstream. In this way, sustainable social practices could become normalised.

Prospective thoughts on softer interventions that might help to encourage shifts in perceptions and practices would begin at the very beginning. Local residents will have the most grounded local knowledge and expertise, and so these voices should be brought in as early as possible into the co-construction and co-development of any proposed SuDS solutions. As was observed in Stroud, designers working alongside residents helped to encourage ownership of devices that fed through to improved understanding and behaviour.

Importantly, engagement should not stop at the point construction finishes. Firstly, as has been mentioned, people will move, and simply forget, due to leading busy lives. Ongoing engagement could help to encourage positive social practices not to drift off people's radar.

Furthermore, in the longer-term, preferences will inevitably change due to shifts in demographics and fashions, and demands upon devices may also change with increased urbanisation and climate change. For both these reasons, redesign and retrofit will over time be both necessary and desirable, and so (possibly lowlevel) ongoing engagement could provide a bet- 
ter understanding of system needs and community preferences.

To this end, fostering longitudinal engagement practices such as Stewards and Friends of groups, with staff at the relevant authority level who are provided time to engage with and further develop such endeavours and resources to repeatedly get out to, and known by, communities, could help devices to come to be seen as a live concern, part of a conversation rather than simply static authority-level impositions upon communities.

Innovative means of engagement could usefully be pursued, employing all modern forms of communication and social media to encourage people to feel they have voice. All potential beneficiaries of SuDS' multiple benefits should be brought into the conversations so that they appreciate and look to make use of devices' potentialities (such as schools, hospitals and natural history groups). From these conversations further groups and individuals would be found who could benefit, or who have issues with, designs as they stand, and this process of dialogue could help in looking to develop a maximally satisfactory set of solutions.

\section{Conclusion}

This paper has argued that SuDS can be an effective approach to dealing with flood events and can potentially bring with them a whole range of further multiple benefits. However, in order for them to have a reasonable operating life, it is important that local populations understand their purpose and function, appreciate the services they can potentially provide and so engage in good behaviour around devices, and in times of financial austerity placed upon Local Authorities, that they engage to some degree with voluntary work to help with clearing and maintenance.

To this end, the paper has argued that local populations need to be involved in the co-design of installations so that they can offer local expertise and devices can then be tailored, where possible, towards local preferences. Pre- and post-installation awareness-raising exercises will also be central to encouraging the development of understanding and appreciation. These exercises should then be ongoing, and not seen as simply a 12-18 month first-stage endeavour, as local populations will change and people may forget. Furthermore, tastes will change, and so ongoing engagement could allow for redesign and retrofit endeavours to ensure that $\mathrm{SuDS}$ maintain a continuing relevance and desirability to those living locally and making use of them.

The perceived costs of undertaking repeated engagement exercises should be balanced against the potential savings these could arguably enable:

- Firstly, engagement could encourage better behaviour around systems, reducing maintenance and clearing costs. As engagement hopefully helps to encourages shifts in behaviour, so new and positive social practices may develop such that this positive behaviour gradually becomes the 'new normal';

- Secondly, in so doing the systems should operate more effectively as well as having a longer service life, improving public perceptions of devices that are seen to 'work' and encouraging the normalisation of newer social practices;

- Thirdly, in encouraging better behaviour, engagement could also help to encourage shifts in social practices such that local people begin to get involved with voluntary clearing and low-level maintenance, further reducing operator costs and improving service life (and something that is far more likely to happen if local populations have been involved in the design of systems and so feel more preferably towards them and some sense of co-ownership);

- Finally, through improved behaviour and voluntary involvement, systems will not only perform their flood risk functions more effectively for a longer period of time, but will also be more likely to offer improved multiple benefits services, which could in turn improve public perceptions and so with continued engagement activities may encourage further good behaviour and involvement with voluntary assistance around installation.

In short, the costs of taking a co-design approach and then undertaking longer-term engagement and awareness-raising activities hold the potential to reap back multiple benefits in terms of direct costsavings, device functionality, enhancements in the delivered multiple benefits and services, and so improvements in public 
perceptions and endorsement of their further rollout and cover for maintenance costs. The 'costs' of co-design and engagement might thereby initiate a virtuous circle feedback loop enabling savings over the medium- to longer-term and helping to shift social practices, such that approval for and appropriate behaviour around SuDS becomes the new 'normal'.

\section{References}

1. Environment Agency (2009) Flooding in England: A national assessment of flood risk. Bristol: Environment Agency.

2. Environment Agency (2009) Flooding in Wales: A national assessment of flood risk. Bristol: Environment Agency.

3. DEFRA (2012) Floods and Coastal Erosion. London: Defra.

4. Milly P.C.D., Wetherald R.T., Dunne K.A. and Delworth T.L. (2002) Increasing Risk of Great Floods in a Changing Climate. Nature 415, 514-517.

5. Min S-K., Zhang X., Zwiers F.W. and Hegerl G.C. (2011) Human contribution to more-intense precipitation extremes. Nature 470, 378-81.

6. Allan R.P. (2011) Climate change: Human influence on rainfall. Nature 470, 344-345.

7. Pall P., Aina T., Stone D.A., Stott P.A., Nozawa T. and Hilberts A.G.J. (2011) Anthropogenic greenhouse gas contribution to flood risk in England and Wales in autumn 2000. Nature 470, 382-385.

8. Abbott J., Davies P., Simkins P., Morgan C., Levin D. and Robinson P. (2013) Creating $\mathrm{Wa}$ ter Sensitive Places, C724. London: CIRIA.

9. Met Office (2014) The Recent Storms and Floods in the UK. Exeter: Met Office.

10. King D.A (2004) Climate change science: adapt, mitigate, or ignore? Science 303, 176-7.

11. United Nations (2014) World Urbanization Prospects: The 2014 Revision, Highlights (ST/ESA/SER.A/352). Washington: United Nations.

12. Jha A.K., Bloch R., and Lamond J. (2012) Cities and Flooding. Washington: World Bank.
13. Wheater H. and Evans E. (2009) Land use, water management and future flood risk. Land Use Policy. 26, 251-64.

14. Hoyer J., Dickhaut W., Kronwitter L. and Weber B. (2011) Water Sensitive Urban Design: Principles and Inspiration for Sustainable Stormwater Management in the City of the Future. Berlin: Jovis.

15. Wong T.H.F. Allen R., Brown R. et al. (2013) blueprint2013: Stormwater Management in a Water Sensitive City. Adelaide: CRCWSC.

16. EU (2000) Water Framework Directive. Brussels: European Commission.

17. EU (2009) Floods Directive. Brussels: European Commission.

18. Rijke J., van Herk S., Zevenbergen C. and Ashley R. (2012) Room for the River: delivering integrated river basin management in the Netherlands. International Journal of River Basin Management. IAHR 10, 369-82.

19. Department for Environment, Food and Rural Affairs (2005) Making space for water. London: Defra.

20. Scottish Environment Protection Agency (2009) Flooding in Scotland: A consultation on Potentially Vulnerable Areas and Local Plan Districts. Edinburgh: SEPA.

21. Department of Environment, Water and Natural Resources (2014) Revised Planning Policy Statement 15: 'Planning and Flood Risk'. Belfast: DOENI.

22. Welsh Government (2011) National Strategy for Flood and Coastal Erosion Risk Management in Wales. Cardiff: Welsh Government.

23. Environmental Protection Agency (2007). Reducing Stormwater Costs through Low Impact Development (LID): Strategies and Practices. Washington, DC: EPA.

24. Environmental Protection Agency (2013) Stormwater to Street Trees. Washington, DC: EPA.

25. Benedict M.A., McMahon E.T. and Fund M.A.T.C. (2012) Green Infrastructure. Washington, DC: Island Press..

26. Portney K.E. (2013) Taking Sustainable Cit- 
ies Seriously. Massachusetts: MIT Press.

27. Mayer H. and Provo J. (2004) The Portland Edge in Context. C.P. Ozawa (ed.) The Portland Edge: Challenges and successes in growing communities. Washington, DC: Island Press.

28. Bureau of Environmental Services (2001) Johnson Creek Restoration Plan. Portland: BES.

29. Saha D., Paterson R.G. (2008) Local Government Efforts to Promote the "Three Es" of Sustainable Development: Survey in Medium to Large Cities in the United States. Journal of Planning Education and Research, 28, 21-37.

30. Slavin M. (2013) Sustainability in America's Cities. Washington, DC: Island Press.

31. Shandas V, Nelson A, Arendes C and Cibor C (2010) Tabor to the River: An evaluation of outreach efforts and opportunities for engaging residents in stormwater management.

32. Susdrain (2012) Sustainable Drainage. London: Susdrain.

33. Department for Environment, Food and Rural Affairs (2011) Flood Risk and Insurance: $A$ roadmap to 2013 and beyond.

34. RSPB (2012) Sustainable drainage systems. London: RSPB.

35. Anglian Water (2009) Guidance on the use of sustainable drainage systems (SUDS) and an overview of the adoption policy introduced by Anglian Water. Huntingdon: Anglian Water.

36. Werritty A., Houston D., Ball T., Tavendale A. and Black A (2007) Exploring the Social Impacts of Flood Risk and Flooding in Scotland. Edinburgh: Scottish Executive.

37. Johnson C.L. and Priest S.J. (2008) Flood Risk Management in England: A Changing Landscape of Risk Responsibility? International Journal of Water Resources Development, 24, 513-25.

38. Kenyon W. (2007) Evaluating flood risk management options in Scotland: A participantled multi-criteria approach. Ecological Economics, 64, 70-81.

39. Apostolaki S. and Jefferies C. (2005) Social impacts of stormwater management techniques including river management and SUDS. Final report, SUDS01. Bristol: Environment Agency.

40. HR Wallingford (2003) An Assessment of the Social Impacts of Sustainable Drainage Systems in the UK. Wallingford: HR Wallingford.

41. Bastien N.R.P., Arthur S. and McLoughlin M.J. (2011) Valuing amenity: public perceptions of sustainable drainage systems ponds. Water \& Environment Journal. 26, 19-29.

42. Shandas V. (2015) Neighborhood change and the role of environmental stewardship: a case study of green infrastructure for stormwater in the City of Portland, Oregon, USA. Ecology and Society. 20(3): 16.

43. Church S.P. (2015) Exploring Green Streets and rain gardens as instances of small scale nature and environmental learning tools. Landscape and Urban Planning. 134, 229-40.

44. Baert P., da Silva F.C. (2010) Social Theory in the Twentieth Century and Beyond. Cambridge: Polity Press.

45. Reckwitz A. (2002) Toward a Theory of Social Practices: A Development in Culturalist Theorizing. European Journal of Social Theory, 5, 243-63.

46. Schatzki T.R. (1996) Social Practices. Cambridge: Cambridge University Press.

47. Spaargaren G. (2011) Global Environmental Change. Global Environmental Change, 21, 813-22.

48. Warde A. (2005) Consumption and Theories of Practice. Journal of Consumer Culture, $\mathbf{5}$, 131-53.

49. Shove, E. and Southerton, D. (2000) Defrosting the Freezer: From Novelty to Convenience: A Narrative of Normalization. Journal of Material Culture, 5, 301-319.

50. Shove, E., Pantzar, M. and Watson, M. (2012) The Dynamics of Social Practice: Everyday life and how it changes. London: SAGE.

51. Shove E. (2005) Consumers, Producers and Practices: Understanding the invention and reinvention of Nordic walking. Journal of Consumer Culture, 5, 43-64.

52. Shove E (2010) Beyond the ABC: climate change policy and theories of social change. En- 
viron. Plann. A, 42, 1273-85.

53. Spaargaren G. and Mol A (2008) Greening global consumption: Redefining politics and authority. Global Environmental Change, 18, 3509.

54. Spurling N., McMeekin A., Shove E., Southerton D. snd Welch D (2013) Interventions in practice: re-framing policy approaches to consumer behaviour. Manchester: Sustainable Practices Research Group.

55. Glover A. (2013) Should it Stay or Should it Go?: Social Practices of Material Divestment. SCORAI Conference, Clark University, Massachusetts.

56. Hackett B. and Lutzenhiser L (1985) The unity of self and object. Western Folklore, 44, 317-24.

57. Singleton D (2012) SuDS in the community: a suitable case for treatment? London: Susdrain.

58. Franklin J.F. (2008) Preserving Biodiversity: Species, Ecosystems, or Landscapes? Ecological Applications, 3:2, 202-205.

59. Purvis A. and Hector A. (2000) Getting the measure of biodiversity. Nature. 405, 212-9.

60. Hanley N., Spash C. and Walker L. (1995) Problems in valuing the benefits of biodiversity protection. Environ Resource Econ. 5, 249-72.

61. Chiesura A. (2004) The role of urban parks for the sustainable city. Landscape and Urban Planning, 68, 129-38.

62. Swanwick C., Dunnett N. and Woolley H. (2003) Nature, role and value of green space in towns and cities: An overview. Built Environment, 29, 94-106.

63. Coley R.L., Sullivan W.C. and Kuo F.E. (1997) Where Does Community Grow? The Social Context Created by Nature in Urban Public Housing. Environment and Behavior, 29, 46894.

64. Dunnett N. and Qasim M. (2000) Perceived Benefits to Human Well-being of Urban Gardens. HortTechnology. 10, 40-5.

65. Barbosa O., Tratalos J.A., Armsworth P.R., Davies R.G., Fuller R.A., Johnson P., et al. (2007) Who benefits from access to green space? A case study from Sheffield, UK. Landscape and Urban Planning, 83, 187-95.

66. Fuller R.A., Irvine K.N., Devine-Wright P., Warren P.H. and Gaston K.J. (2007) Psychological benefits of greenspace increase with biodiversity. Biology Letters, 3, 390-4.

67. Carrus G., Scopelliti M., Lafortezza R., Colangelo G., Ferrini F., Salbitano F., et al. (2015) Go greener, feel better? The positive effects of biodiversity on the well-being of individuals visiting urban and peri-urban green areas. Landscape and Urban Planning, 134, 221-8.

68. Krekel C., Kolbe J. and Wüstemann H. (2016) The greener, the happier? The effect of urban land use on residential well-being. Ecological Economics, 121, 117-27.

69. Barnhill K. and Smardon R. (2012) Gaining Ground: Green Infrastructure Attitudes and Perceptions from Stakeholders in Syracuse, New York. Environmental Practice, 14, 6-16.

70. LaBadie K. (2010) Identifying Barriers to Low Impact Development and Green Infrastructure in the Albuquerque Area. Master of Water Resources Professional Project Proposal, University of New Mexico.

71. Traver R.G. (2009) Efforts to address urban stormwater runoff. Statement before the Subcommittee on Water Resources and Environment, U.S. House of Representatives.

72. Everett G., Lamond J.E., Morzillo A.T., Matsler A.M., Chan F.K.S. (2016) Delivering Green Streets: an exploration of changing perceptions and behaviours over time around bioswales in Portland, Oregon. Journal of Flood Risk Management [online].

73. Everett G., Lamond J.E., Morzillo A.T., Matsler A.M., Chan F.K.S. (2015) Sustainable drainage systems: Helping people live with water. Proceedings of the ICE - Water Management [online].

74. Bureau of Environmental Services (2012) The Green Street Steward's Maintenance Guide. Portland: BES.

75. Furnham A. (1986) Response bias, social desirability and dissimulation. Personality and Individual Differences, 7, 385-400.

76. Whitehead J.C. (1991) Environmental In- 
terest Group Behavior and Self-Selection Bias in Contingent Valuation Mail Surveys. Growth and Change, 22, 10-20. 